\title{
The Effect of Individualised Glycemic Intervention on Wound Healing Rate in Diabetic Foot Ulcer (The EIGIFU Study)*
}

\author{
Kim Piow Lim, ${ }^{1}$ Azraai Bahari Nasruddi, ${ }^{1}$ Noraishah Md Rani² \\ ${ }^{1}$ Endocrine Unit, Department of Medicine, Hospital Putrajaya, Putrajaya, Malaysia \\ ${ }^{2}$ Wound Care Unit, Hospital Putrajaya, Putrajaya, Malaysia
}

\begin{abstract}
Objective. To evaluate the association of glycated haemoglobin $\left(\mathrm{HbA}_{1 \mathrm{c}}\right)$ reduction and wound healing in patients with diabetic foot ulcer (DFU).

Methodology. A 12-week prospective, non-controlled, interventional study in suboptimal-controlled T2DM patients with DFU was conducted. Antidiabetic medications were adjusted with the aim of at least $1 \%$ in relation to patient's individualised $\mathrm{HbA}_{1 \mathrm{c}}$ target. The wound area was determined by using specific wound tracing. The daily wound area healing rate in $\mathrm{cm}^{2}$ per day was calculated as the difference between wound area at first visit and the subsequent visit divided by the number of days between the two visits.

Results. 19 patients were included in the study. There was a significant $\mathrm{HbA}_{1 \mathrm{c}}$ reduction from $10.33 \% \pm 1.83 \%$ to $6.89 \%+1.4 \% \quad(p<0.001)$ with no severe hypoglycaemia. The median daily wound area healing rate was 0.234 $(0.025,0.453) \mathrm{cm}^{2} /$ day. There was a strong positive correlation between these two variables $(r=0.752, p=0.01)$. After dividing the patients into four quartiles based on final $\mathrm{HbA}_{1 \mathrm{c}}$ and comparing the first quartile vs fourth quartile, there was a significant difference in daily wound area healing rates $\left(0.597 \mathrm{vs} 0.044 \mathrm{~cm}^{2} /\right.$ day, $\left.p=0.012\right)$.

Conclusion. There was a positive correlation between $\mathrm{HbA}_{1 \mathrm{c}}$ reduction and wound healing rate in patients with DFU. Although this is an association study, the study postulated the benefits of achieving lower $\mathrm{HbA}_{1 \mathrm{c}}$ on wound healing rate in DFU which require evidence from future randomised controlled studies.
\end{abstract}

Key words: diabetic foot ulcer, individualised glycemic intervention, wound healing

\section{INTRODUCTION}

Diabetic Foot Ulcer (DFU) is a common complication of Diabetes Mellitus (DM) that has increased dramatically over previous decades. ${ }^{1,2}$ The lifetime risk of a foot ulcer in patients with diabetes (type 1 or 2 ) may be as high as $25 \% .^{3}$ $\mathrm{DFU}$ is one of the major causes of morbidity and mortality accounting for approximately two-thirds of all nontraumatic amputations performed in the United States. ${ }^{3}$ In Malaysia, foot complications accounted for approximately $12 \%$ of all diabetic hospital admissions. ${ }^{4}$ In Hospital Kuala Lumpur, which is the main public tertiary medical center in Malaysia, around $17 \%$ of diabetic patients were admitted because of diabetic foot ulcer (DFU). ${ }^{5}$

DFU is defined as a non- or poorly healing, partial or full thickness wound, located distal to the ankle in an individual with DM. The common sites involved are the sole of the foot or the toes. ${ }^{6}$ Once DFU has developed, there is an increased risk of ulcer progression that may

ISSN 0857-1074 (Print) I ISSN 2308-118x (Online)

Printed in the Philippines

Copyright (C) 2018 by the JAFES

Received: February 6, 2018. Accepted: March 16, 2018.

Published online first: April 4, 2018.

https://doi.org/10.15605/jafes.033.01.04 ultimately lead to amputation. Overall, the rate of lower limb amputation in patients with DM is 15 times higher than patients without diabetes. ${ }^{7}$ Furthermore, DFU is responsible for substantial emotional and physical distress as well as productivity and financial losses that lower the quality of life. ${ }^{8}$

The primary management goal for DFU is to obtain wound closure as expeditiously as possible. ${ }^{9,10}$ However, glucose control measured by glycated hemoglobin ( $\left.\mathrm{HbA}_{1 \mathrm{c}}\right)$ level is the most important metabolic factor. ${ }^{11,12} \mathrm{HbA}_{1 \mathrm{c}}$ level measures the average blood sugar concentration over a 90 day span of the average red blood cell in peripheral circulation. In the UKPDS, it was clearly shown that a $1 \%$ mean reduction in $\mathrm{HbA}_{1 \mathrm{c}}$ is associated with a $25 \%$ reduction in microvascular complications, including neuropathy. ${ }^{13}$ Poor glucose control accelerated the manifestation of peripheral arterial disease (PAD) which is a primary cause of DFU. ${ }^{13}$ Meta-analysis of nine trials enrolling 19,234 patients showed that compared with less

Corresponding author: Kim Piow Lim, MD

Fellow, Endocrine Unit, Department of Medicine

Hospital Putrajaya, Putrajaya Pentadbiran Kerajaan Persekutuan Presint 7

62250 Putrajaya, Wilayah Persekutuan, Putrajaya, Malaysia

Tel. No.: 603-83124200

Fax No.: 603-88880137

E-mail: piow2005@gmail.com

ORCID iD: https://orcid.org/0000-0002-9189-9052

*This study was presented as oral presentation at the 7th National Wound Conference on 18-20 July 2017 at Everly Hotel, Putrajaya, Malaysia and 19th ASEAN Federation of Endocrine Societies Congress on 9-12 November 2017 at Yangon, Myanmar. 
intensive glycemic control, intensive control ( $\mathrm{HbA} 1 \mathrm{c}, 6 \%$ $7.5 \%$ ) was associated with a significant decrease in risk of amputation (relative risk [RR], 0.65; 95\% confidence interval [CI], 0.45-0.94; $\left.\mathrm{I}^{2}=0 \%\right) .{ }^{14}$

One of the retrospective studies demonstrated that single blood glucose level $>12.2 \mathrm{mmol} / \mathrm{L}$ on the first postoperative day was a sensitive $(87.5 \%)$ predictor of postoperative infection. ${ }^{15}$ Recently, a retrospective study showed that there was a significant association between $\mathrm{HbA}_{1 c}$ variability and healing time in diabetic foot ulcers. Additionally, the study also highlighted that time to healing is more dependent on the mean $\mathrm{HbA}_{1 c}$ than the variability in $\mathrm{HbA}_{1 \mathrm{c}}(p=0.007) .{ }^{16}$

However, to date, no prospective study has been performed to assess the effect of glycemic control to decrease $\mathrm{HbA}_{1 \mathrm{c}}$ levels has benefits in wound healing after a foot ulcer has developed. ${ }^{17}$ This is a pilot study conducted with the main objective of evaluating the association of $\mathrm{HbA}_{1}$ reduction and wound healing rate.

\section{METHODOLOGY}

\section{Study design}

A 12-week prospective, non-controlled, interventional study in subjects with suboptimally controlled T2DM patients with DFU was conducted from June to December 2016 at the Wound Unit, Hospital Putrajaya. The study was approved by the local institutional review board. Informed patient consent was obtained.

\section{Study population}

Majority of patients were referred by the Health Clinic from Wilayah Persekutuan Putrajaya, Malaysia to improve and optimise the risk factors for management of wound healing. The dedicated wound team consisted of 3 medical officers and 3 staff nurses. All wound treatments were performed for all patients with diabetic wounds according to the Standard Operation Procedure (SOP) of the wound clinic including removal of non-viable tissue, local dressing (antimicrobial dressings with silver), offloading with proper shoes and antibiotic treatment if infection was present. However, patients' glycaemia were not monitored at the wound clinic. Their glycaemic control and cardiovascular risk factors were managed by their respective doctors from the health clinic or specialists at the hospital.

\section{Study patients}

Eligible T2DM patients with DFU aged 20 to 75 years old who had baseline $\mathrm{HbA}_{1 c} 1 \%$ higher than the target were recruited to the study. The target $\mathrm{HbA}_{1 c}$ was determined at the first visit based on the patient's age, duration of DM, comorbid, diabetic complications, life expectancy and risks of hypoglycemia, according to Clinical Practice Guidelines
- Management of Type 2 Diabetes Mellitus ( $5^{\text {th }}$ edition). ${ }^{18}$ Exclusion criteria were patients with acute and ongoing osteomyelitis or venous ulcer, patients with ankle brachial blood pressure ratio less than 0.5 suggesting severe limb ischemia, history ( $\geq 2$ events) of hypoglycemic seizure or hypoglycemic coma within the last 6 months, patients with end stage renal disease, severe heart failure with New York Heart Association (NYHA) class IV, thromboembolic disease within the last 3 months, severe liver failure with Child-Pugh class C, history of schizophrenia, alcohol or drug abuse, and pregnant women. This study was approved by Malaysia Medical Research and Ethics Committee and was done in adherence to the Helsinki Guidelines. Written informed consent was taken during the first visit.

\section{Study interventions}

There were 5 visits during the study, i.e., week 0 , week 2 , week 4, week 8 and week 12. For each patient, demographic data, clinical data and laboratory biochemistry were collected including full blood count, renal function, liver function, $\mathrm{HbA}_{1 \mathrm{c}}$ and lipid profile. Biochemical investigation was obtained during the first clinic visit and week 12 of the clinic visit. Renal function was evaluated by estimated glomerular filtration rate (eGFR) using Modification of Diet in Renal Disease formula. Detailed history and physical examination were performed.

Complication assessments including microvascular (retinopathy, nephropathy and neuropathy) and macrovascular (ischemic heart disease, stroke and peripheral vascular disease) were documented. During visits to the Wound Unit, blood pressure, pulse, and temperature were measured with the individual in a sitting position using standard clinical procedure. Associated cardiovascular risk factors including smoking, hypertension, dyslipidaemia as well as their treatment were ascertained.

\section{Wound assessment}

Detailed wound assessment was performed. Wound ulcer severity was graded by Wagner's grading system from grade 1 to 5 . Any presence of foot deformity, high plantar pressure, infections, inappropriate foot self- care, trauma, fracture, callus and amputation were documented. Serial wound areas, as determined by specific wound tracing grid at each visit, were indicative of the wound healing ${ }^{19}$ (Figure 1). Initially, the wound tracing grid was put over the wound and area was traced on the grid. The superficial layer was peeled off and placed on a piece of paper. Subsequently, the wound area would be calculated using grid in $\mathrm{cm}^{2}$. The daily wound area healing rate in $\mathrm{cm}^{2}$ per day was calculated as the difference between wound area at the first visit and the subsequent visits, divided by the number of days between the two visits. In order to avoid measurement bias, an accurate measurement 

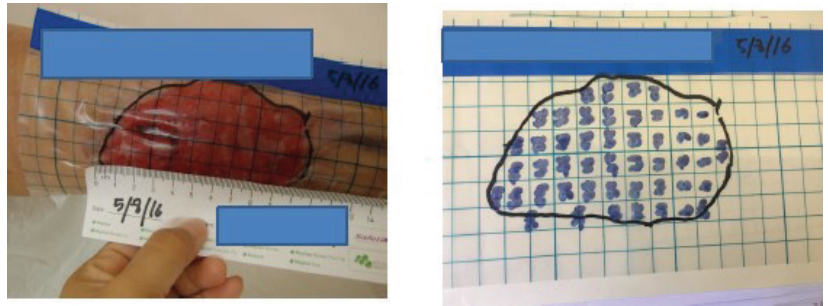

(a) Visit 1
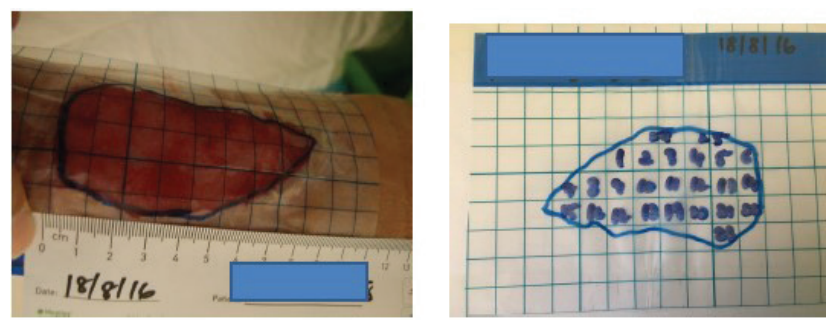

(b) Visit 2

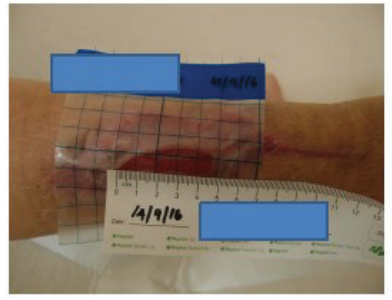

(c) Visit 3

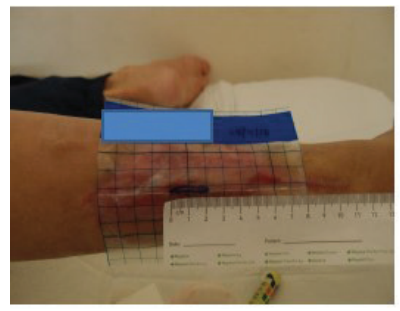

(d) Visit 4

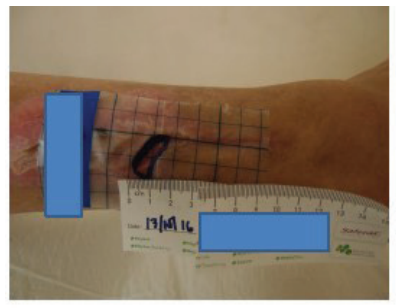

(e) Visit 5

Figures 1(a-e). Measurement of wound area via wound area tracing at visits 1 to 5 .

of the wound size was made by the same clinician by wound tracing and validated by a third independent clinician.

\section{Individualised glycaemic intervention}

The individualised glycaemic intervention was a continuous, integrated patient-centred care involving clinicians, staff nurses, nutritionists and diabetic educators. The areas emphasized included Medical Nutrition Therapy, Exercise Therapy, Diabetic Complications, Drug Adherence, Usage of Antidiabetic agents including Insulin Therapy, Hypoglycaemia
Management, Self-Monitoring Blood Sugar (SMBG) with diary record, weight control, stress management, etc. We utilised social media and electronic devices as main communication tools in educating the patients.

Antidiabetic medications including insulin therapy or oral antidiabetic agents (OADs) were adjusted or added with the aim of reducing $\mathrm{HbA}_{1 c}$ by at least $1 \%$ in relation to patient's individualised $\mathrm{HbA}_{1 c}$ target which was described above. Glucose meters and strips were given free to patients and SMBG with diary record was required at least 4 times per day (premeals and pre-bedtime) 3 times per week. Patients were encouraged to perform blood sugar checks whenever they were unwell or symptomatic for hypoglycemia. An ongoing insulin titration was performed actively in those patients whose glycaemia was not within the target range (including hypoglycemia) by the investigators or medical officers within the 12 weeks of their wound clinic visits. The titration of insulin was based on individualised titration protocol (based on Ministry of Health Clinical Practice Guidelines on Insulin Therapy). ${ }^{18,20}$ Antihypertensive and lipid lowering therapies were allowed to be added or adjusted depending on investigator's discretion. The result of the glycemic intervention were expressed in absolute $\mathrm{HbA}_{1 c}$ reduction and relative $\mathrm{HbA}_{1 c}$ reduction rates calculated as the percentage of difference of first and final $\mathrm{HbA}_{1 c}$ divided by first $\mathrm{HbA}$ c. Both were expressed in percentages (\%).

\section{Statistical analysis}

All statistical analyses were performed using the Statistical Package for Social Science version 22.0 for Windows (SPSS Incorporation, Chicago, Illinois, USA). Descriptive analysis was used to explain demographic and clinical data. Numerical values for parametric and non-parametric variables were expressed as mean $+/$ - standard deviation (SD) and median +/- Interquartile range (IQR). Categorical data were expressed as number and percentage. Spearman's correlation was used to measure the strength and direction of association between the $\mathrm{HbA}_{1 c}$ reduction rate and the daily wound area healing rate. The patients were divided into 4 quartiles based on final $\mathrm{HbA}_{1 \mathrm{c}}$ and the daily wound area healing rate for the first and fourth quartiles were compared via Wilcoxon signed rank test. A $p$ value of $<0.05$ was considered statistically significant.

\section{RESULTS}

\section{Patient characteristics}

There were 25 patients screened and recruited. Four patients had screening failure, including three who failed to meet the $\mathrm{HbA}_{1 c}$ criteria and two patients withdrew voluntarily from the study in the early period. Therefore, 19 patients (Table 1) completed the study. Their mean age and mean age of diagnosis of DM were $48.9 \pm 12.2$ years and $37.1 \pm 9.5$ years respectively. They were mainly males $15 / 19(79 \%)$ and of Malay ethnicities 15/19 (79\%). Their 
mean duration of DM and median duration of DFU were $10.8 \pm 6.7$ years and $3(2,6.5)$ months respectively. Macrovascular complications were present in $3(16 \%)$ patients with the following distribution: ischemic heart disease $1(5 \%)$, cerebrovascular disease (stroke) 2 (11\%) and peripheral vascular disease with 3 (16\%). All 19 patients $(100 \%)$ had microvascular complications specifically retinopathy and neuropathy, and 14 (79\%) patients had nephropathy. Forty eight percent and 26\% of patients had target $\mathrm{HbA}_{1 \mathrm{c}}$ of $6.5-7 \%$ and $7-7.5 \%$ respectively.

\begin{tabular}{|c|c|}
\hline $\begin{array}{l}\text { Table 1. Patient } \\
\text { characteristics }\end{array}$ & demographic and clinical \\
\hline Clinical Parameters & N (\%) / Mean (SD)/Median (IQR) \\
\hline Age (year) & $48.9(12.2)$ \\
\hline \multicolumn{2}{|l|}{ Gender } \\
\hline Male & $15(79 \%)$ \\
\hline Female & $4(21 \%)$ \\
\hline \multicolumn{2}{|l|}{ Ethnicity } \\
\hline Malay & $15(78 \%)$ \\
\hline Chinese & $2(11 \%)$ \\
\hline Indian & $2(11 \%)$ \\
\hline Age of Diagnosis (year) & $37.1(9.5)$ \\
\hline Duration of Diabetes (year) & $10.8(6.7)$ \\
\hline Duration of DFU (month) & $3(2,6.5)$ \\
\hline \multicolumn{2}{|l|}{ Smoking history } \\
\hline Active & $1(4 \%)$ \\
\hline Previous/ Never & $18(96 \%)$ \\
\hline Hypertension & $13(68 \%)$ \\
\hline Dyslipidemia & $18(95 \%)$ \\
\hline Overweight / obesity & $15(79 \%)$ \\
\hline Body Mass Index ( kg/m²) & $27.1(5.1)$ \\
\hline $\mathrm{sBP}(\mathrm{mmHg})$ & $128(10)$ \\
\hline $\mathrm{dBP}(\mathrm{mmHg})$ & $80(5)$ \\
\hline $\mathrm{Hb}(\mathrm{g} / \mathrm{dL})$ & $11.6(1.5)$ \\
\hline $\operatorname{WBC}\left(\times 10^{9} \mathrm{~L}\right)$ & $10.8(3.2)$ \\
\hline Platelet $\left(X 10^{9} \mathrm{~L}\right)$ & $386(121)$ \\
\hline Albumin (g/dL) & $32.5(11.25)$ \\
\hline $\operatorname{ALT}(\mathrm{mmol} / \mathrm{L})$ & $14.5(12.3,22.5)$ \\
\hline eGFR $\left(\mathrm{ml} / \mathrm{min} / 1.73 \mathrm{~m}^{2}\right)$ & $79(23)$ \\
\hline \multicolumn{2}{|c|}{$\begin{array}{l}\mathrm{HbA}_{1 \mathrm{c}} \text {, glycated haemoglobin; sBP, systolic blood pressure; } \mathrm{dBP} \text {, } \\
\text { diastolic blood pressure; Heamogloblin; WBC, white blood cell; } \mathrm{ALT} \text {, } \\
\text { Alanine Aminotransferase; eGFR, estimated glomerular filtration rate }\end{array}$} \\
\hline
\end{tabular}

\section{Antidiabetic agents}

The patient's baseline antidiabetic medications were mainly insulin ( $n=18,95 \%)$ and Metformin $(n=12,63 \%)$. The 3 main additional antidiabetic agents were Metformin ( $n=6,32 \%)$, Dipeptidyl peptidase-4 inhibitor (DPP4i) (n=4, 26\%) and Sulphonylurea (n=2, 16\%). During the first visit, 18 (95\%) patients were on insulin therapy and 1 (5\%) patient was on oral monotherapy. Among the patients on insulin, 11 (61\%) were on combination of insulin therapy and one OAD. During the final visit, $2(11 \%)$ patients were on two OADs and 17 $(89 \%)$ patients were on insulin therapy. Among the patients on insulin, $12(71 \%)$ were on combination with one OAD and $5(29 \%)$ were on two OADs.

\section{Wound characteristics}

The median ankle-brachial pressure index for left lower limb and right lower limb was $1.07(1,1.16)$ and 1.05 $(0.95,1.13)$, respectively. Eighty four percent of patients had a single wound. Fifty three percent of patients had foot deformity or Charcot's joint and inappropriate foot care. Seventy four percent of patients had Grade 2 or 3 ulcers according to Wagner's classification of ulcer (Table 2).

\begin{tabular}{ll} 
Table 2. Wound characteristics & \\
\hline Wound numbers & \\
\hline 1 & $16(84 \%)$ \\
2 & $2(11 \%)$ \\
3 & $1(5 \%)$ \\
Deformity / Charcot joint & $10(53 \%)$ \\
Inappropriate foot care & $10(53 \%)$ \\
Infection & $6(32 \%)$ \\
High plantar pressure & $5(27 \%)$ \\
Amputation & $5(27 \%)$ \\
Callus & $2(11 \%)$ \\
Ulcer severity ( Wagner's classification ) & \\
1 & $3(16 \%)$ \\
2 & $6(32 \%)$ \\
3 & $8(42 \%)$ \\
4 & $2(10 \%)$ \\
5 & --- \\
\hline
\end{tabular}

\section{Glycemic intervention and wound area healing rate}

Eighteen (95\%) patients had $\mathrm{HbA}_{1 c}$ reduction and 12 (63\%) patients achieved the prespecified individualised target $\mathrm{HbA}_{1 c}$. The mean $\mathrm{HbA}_{1 c}$ reduction rate was $31.2 \% \pm 7.5 \%$ and the median daily wound area healing rate was $0.234(0.025,0.453) \mathrm{cm}^{2} /$ day. There was a significant mean $\mathrm{HbA}_{1 c}$ reduction from $10.33 \% \pm 1.83 \%$ to $6.89 \% \pm 1.4 \% \quad(p<0.001)$ and mean total daily insulin reduction from $70.4 \mathrm{IU} \pm 19.6$ IU to $41.6 \mathrm{IU} \pm 13.8 \mathrm{IU}$ $(p<0.001)$. Spearman correlation analysis revealed that there was a strong positive correlation between the mean $\mathrm{HbA}_{1 \mathrm{c}}$ reduction rate and median daily wound area healing rate. $(\mathrm{r}=0.752, p=0.01)$ (Figure 2$)$. After dividing the

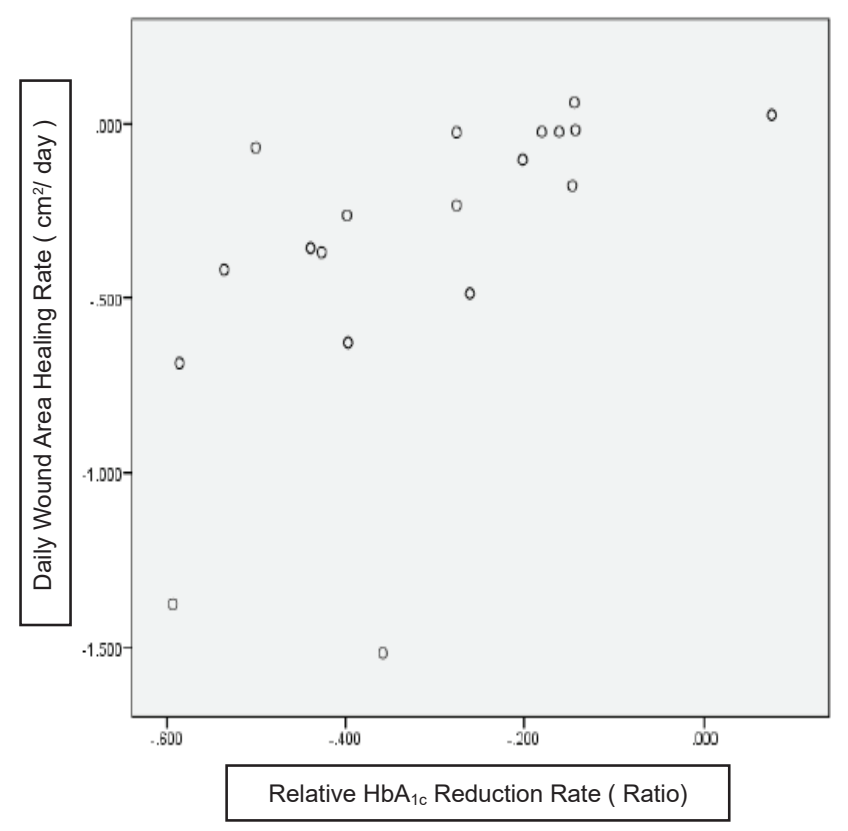

Figure 2. Correlation between the daily wound area healing rate and relative $\mathrm{HbA}_{1 \mathrm{c}}$ Reduction Rate. Spearman correlation analysis revealed that there was a strong positive correlation between the two variables. $(r=0.752$, $p=0.01)$. 
patients into four quartiles based on final $\mathrm{HbA}_{1 c}$ and comparing the first quartile vs fourth quartile, there was a significant difference of daily wound area healing rate (0.597 vs $0.044 \mathrm{~cm}^{2} /$ day, $p=0.012$ ). (Figure 3)

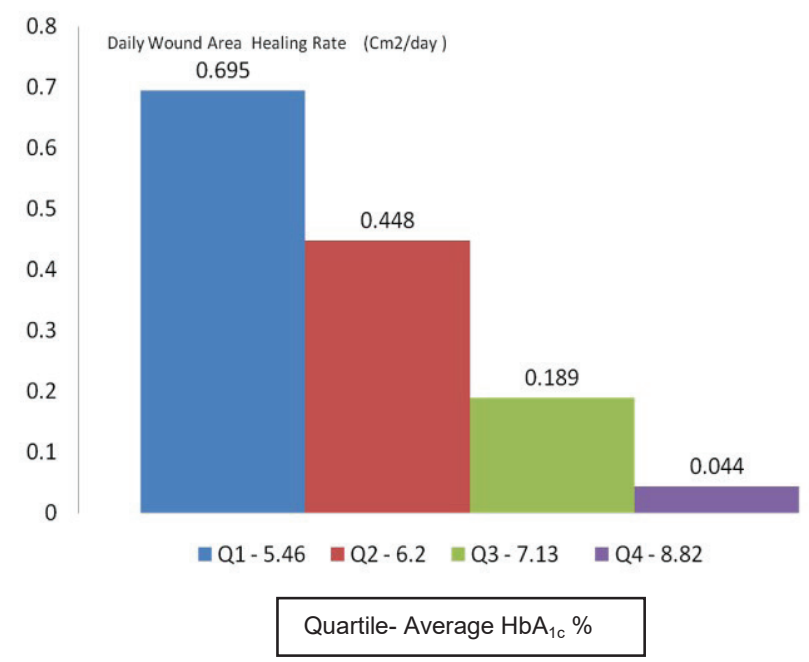

Figure 3. Daily wound area healing rate based on $1^{\text {st }}-4^{\text {th }}$ quartiles of final $\mathrm{HbA}_{1 \mathrm{c}}$.

\section{DISCUSSION}

There was a significant positive correlation between $\mathrm{HbA}_{1 c}$ reduction rate and wound area healing rate. The lower the final $\mathrm{HbA}_{1}$, the faster the wound healed. The higher reduction of $\mathrm{HbA}_{1 \mathrm{c}}$ rate, the faster rate of wound healing compared to those who had lower $\mathrm{HbA}_{1 \mathrm{c}}$ reduction rate.

In this 12 -week study, $95 \%$ and $63 \%$ of patients had $\mathrm{HbA}_{1 \mathrm{c}}$ reduction and achieved prespecified individualised target $\mathrm{HbA}_{1 c}$ respectively. The mean $\mathrm{HbA}_{1 c}$ reduction was $3.44 \%$ and the $\mathrm{HbA}_{1 c}$ reduction rate was $33 \%$. Yet the insulin requirement in our study was reduced by $41 \%$ accompanied by reduction of hypoglycemia events without any significant weight changes. Their baseline antidiabetic medications were mainly insulin (95\%) and metformin (63\%). metformin (32\%), DPP4i (26\%) and sulphonylureas (16\%) were the 3 main additional antidiabetic therapies during the study. Numerous randomized controlled trials and large observational studies have shown that insulin is the antidiabetic agent which has the greatest glucose lowering capacity, if compared with the other OADs. ${ }^{13,21}$ Therefore, insulin therapy was the major therapy to achieve the significant $\mathrm{HbA}_{1 c}$ reduction, albeit there were additions of new OADs. The only explanation of the reduction of insulin to achieve the $\mathrm{HbA}_{1 c}$ reduction was that the patients in the study had poor compliance to insulin therapy prior to the study.

The effective communication between patient and health care provider plays an essential part in managing patients with DFU. It provided adequate time and space and promote rapport, confidence, motivation and satisfaction for both parties. Individualised glycemic intervention in patients with DFU is a holistic tailored approach adapting to patient's values, goal and preference, family, educational, socio-cultural, and occupational background. As diabetes is a multi-organ systemic disease, all comorbidities that affect wound healing must be managed by a multidisciplinary team to reduce amputation rates, lower costs, and lead to better quality of life. ${ }^{22-24}$ Through structured education and selfmanagement programmes, patients will be more adherent to the treatment, which have been shown to improve personal responsibility especially to their own medications. $^{25}$

This is the pilot prospective study examining the association between individualised glycemic interventions and wound healing rate in patients diagnosed with DFU. The study was done in a specified wound clinic that allowed adequate facilities and expertise for patient care. There were certain limitations in the study including the small number of patients from a single center in a short duration of study period. Due to the reasons above, this study was designed as an uncontrolled study that would not provide a proper comparison of efficacy and safety of the intervention. The other limitation was the variable patients' clinical conditions and wound characteristics with different wound treatment that might influence the results of the study. Ideally, a large number of patients from multiple centers including primary, secondary as well as tertiary health facilities should be examined to minimize the impact of the selection bias. Individualised glycaemic intervention should be integrated into multidisciplinary team approach in order to have better wound healing in patients with DFU.

\section{CONCLUSION}

There was a positive correlation between $\mathrm{HbA}_{1 \mathrm{c}}$ reduction and wound healing rate in patients with DFU. Although this is an association study, the study postulated the benefits of achieving lower $\mathrm{HbA}_{1 c}$ on wound healing rate in DFU which require evidence from future randomised controlled studies.

\section{Acknowledgments}

The authors thank Dr. Siti Norlailli Aiza, Dr Nazirah and the staff nurses at the Wound Clinic (Sister Julizaayu, Sister Norita, SN Anita, SN Marliza), Hisham Abdullah (Diabetic Educator), Puan Norzalinah (Dietitian), Puan Nadiah (Statistician) and the Clinical Research Centre, Hospital Putrajaya for their contributions to this study.

\section{Statement of Authorship}

All authors certified fulfillment of ICMJE authorship criteria.

\section{Author Disclosure}

The authors declared no conflict of interest. 


\section{Funding Source}

The study was funded by Ministry of Health and Abbott Laboratories (M) Sdn. Bhd.

\section{References}

1. Alavi A, Sibbald RG, Mayer D, et al. Diabetic foot ulcers: Part II. management. J Am Acad Dermatol. 2014;70(1):21.e1-2124. PMID: 24355276. https://doi.org/10.1016/j.jaad.2013.07.048.

2. Shahbazian H, Yazdanpanah L, Latifi SM. Risk assessment of patients with diabetes for foot ulcers according to risk classification consensus of International Working Group on Diabetic Foot (IWGDF) Pak J Med Sci. 2013;29(3):730-4. PMID: 24353617. PMCID: PMC3809295.

3. Boulton AJ, Armstrong DG, Albert SF, et al. Comprehensive foot examination and risk assessment: A report of the task force of the foot care interest group pf the American Diabetes Association, with endorsement by the American Association of Clinical Endocrinologists. Diabetes Care. 2008;31(8):1679-85. PMID: 18663232. PMCID: PMC2494620. https://doi.org/10.2337/dc08-9021.

4. Clinical practice guidelines on management of diabetic foot, Academy of Medicine Malaysia and Ministry of Health, Malaysia. 2004. http://www.acadmed.org.my/index.cfm?menuid=67.

5. Khalid BAK. Status of diabetics in Malaysia: In World book of Diabetes in Practice, 7th ed. Elsevier Science Publishers, 1998, pages 341-2.

6. Snyder RJ, Hanft JR. Diabetic foot ulcers--effects on QOL, costs, and mortality and the role of standard wound care and advanced-care therapies. Ostomy Wound Manage. 2009;55(11):28-38. PMID: 19934461.

7. Ragnarson Tennvall G, Apelqvist J. Health-economic consequences of diabetic foot lesions. Clin Infect Dis. 2004;39 Suppl 2:S132-9. PMID: 15306992. https://doi.org/10.1086/383275.

8. Patout CA, Birke JA, Horswell R, Williams D, Cerise FP. Effectiveness of a comprehensive diabetes lower-extremity amputation prevention program in a predominantly low-income African-American population. Diabetes Care. 2000;23(9):1339-42. PMID: 10977029.

9. Cavanagh PR, Lipsky BA, Bradbury AW, Botek G. Treatment for diabetic foot ulcers. Lancet. 2005;366(9498):1725-35. PMID: 16291067. https://doi.org/10.1016/S0140-6736(05)67699-4.

10. Driver VR, Madsen J, Goodman RA. Reducing amputation rates in patients with diabetes at a military medical center: The limb preservation service model. Diabetes Care. 2005;28(2):248-53. PMID: 15677774.

11. Bowering CK. Diabetic foot ulcers. Pathophysiology, assessment, and therapy. Can Fam Physician. 2001;47:1007-16. PMID: 11398715. PMCID: PMC2018500.

12. McMurry JF Jr. Wound healing with diabetes mellitus. Better glucose control for better wound healing in diabetes. Surg Clin North Am. 1984;64(4):769-78. PMID: 6433493.

13. Effect of intensive blood-glucose control with metformin on complications in overweight patients with type 2 diabetes (UKPDS 34) UK Prospective Diabetes Study (UKPDS) Group. Lancet. 1998;352(9131):854-65. PMID: 9742977.
14. Hasan R, Firwana B, Elraiyah T, et al. A systematic review and metaanalysis of glycemic control for the prevention of diabetic foot syndrome. J Vasc Surg. 2016;63(2 Suppl):22S-8S. PMID: 26804364. https://doi.org/ 10.1016/j.jvs.2015.10.005.

15. Pomposelli JJ, Baxter JK 3rd, Babineau TJ, et al. Early postoperative glucose control predicts nosocomial infection rate in diabetic patients. JPEN J Parenter Enteral Nutr. 1998;22(2):77-81. PMID: 9527963. https://doi.org/10.1177/014860719802200277.

16. Dhatariya KK, Li Ping Wah-Pun Sin E, Cheng JOS, et al. The impact of glycaemic variability on wound healing in the diabetic foot - a retrospective study of new ulcers presenting to a specialist multidisciplinary foot clinic. Diab Res Clin Pract. 2018;134:23-9. PMID: 29097286. https://doi.org/10.1016/j.diabres.2017.10.022.

17. Yazdanpanah L, Nasiri M, Adarvishi S. Literature review on the management of diabetic foot ulcer. World J Diabetes. 2015;6(1):37-53. PMID: 25685277. PMCID: PMC4317316. https://doi.org/10.4239/ wjd.v6.i1.37.

18. Clinical practice guideline management of type 2 diabetes mellitus, $5^{\text {th }}$ edition, Ministry of Health, Malaysia. 2015. http://www.moh.gov.my/ penerbitan/CPG/CPG\%20T2DM\%202015.pdf.

19. Khoo R, Jansen S. The evolving field of wound measurement techniques: A Literature Review. Wounds. 2016;28(6):175-81. PMID: 27377609 .

20. Practical guide to insulin therapy in type 2 diabetes mellitus. Ministry of Health and Malaysian Endocrine \& Metabolic Society, Malaysia. 2011. http://www.mems.my/file_dir/3308086634dc0e0f9e1c72.pdf.

21. Schreiber SA, Ferlinz K, Haak T. The long-term efficacy of insulin Glargine plus oral antidiabetic agents in a 32-month observational study of every day clinic practice. Diabetic Technol Ther. 2008, 10(2):121-7. PMID: 18260775. https://doi.org/10.1089/dia.2007.0265.

22. Sumpio BE, Aruny J, Blume PA. The multidisciplinary approach to limb salvage. Acta Chir Belg. 2004;104(6):647-53. PMID: 15663269.

23. Wraight PR, Lawrence SM, Campbell DA, Colman PG. Creation of a multidisciplinary, evidence based, clinical guideline for the assessment, investigation and management of acute diabetes related foot complications. Diabet Med. 2005;22(2):127-36. PMID: 15660728. https://doi.org/10.1111/j.1464-5491.2004.01363.x.

24. Aydin K, Isildak M, Karakaya J, Gürlek A. Change in amputation predictors in diabetic foot disease: Effect of multidisciplinary approach. Endocrine. 2010;38(1):87-92. PMID: 20960107. https://doi.org/ 10.1007/s12020-010-9355-z.

25. Davies MJ, Heller S, Skinner TC, et al. Effectiveness of the diabetes education and self management for ongoing and newly diagnosed (DESMOND) programme for people with newly diagnosed type 2 diabetes: Cluster randomised controlled trial. BMJ. 2008:336(7642);491-5. PMID: 18276664. PMCID: PMC2258400. https://doi.org/10.1136/bmj.39474.922025.BE.

Authors are required to accomplish, sign and submit scanned copies of the JAFES Author Form consisting of: (1) the Authorship Certification that the manuscrip has been read and approved by all authors, and that the requirements for authorship have been met by each author, (2) the Author Declaration that the article represents original material that is not being considered for publication or has not been published or accepted for publication elsewhere, (3) the Statement of Copyright Transferfaccepted manuscripts become the permanent property of the JAFES and are licensed with an Attribution-Share Alike-Non-Commercial Creative Commons License. Articles may be shared and adapted for non-commercial purposes as long as they are properly cited], (4) the Statement of Disclosure that there are no financial or other relationships that might lead to a conflict of interest. For Original Articles involving human participants, authors are required to submit a scanned copy of the Ethics Review Approval of their research. For manuscripts reporting data from studies involving animals, authors are required to submit a scanned copy of the Institutional Animal Care and Use Committee approval. For Case Reports or Series, and Images in Endocrinology, consent forms, are required for the publication of information about patients; otherwise, authors declared that all means have been exhausted for securing such consent. Articles and any other material published in the JAFES represent the work of the author(s) and should not be construed to reflect the opinions of the Editors or the Publisher. 